\title{
ABNORMAL LACTATION IN A GOAT.
}

By E. C. Sparrow, V.S., Rayleigh, Essex.

IN April I 887 a client of mine, Mrs Phillips, Picton House, Rayleigh, purchased a female goat, two years old. The animal was never put to the male, and in the spring of $\mathrm{I} 890$ it commenced to give milk, the quantity averaging about a pint night and morning. This continued until the autumn of 1899 , when the amount gradually diminished until she became dry. At the present time the animal is in good health but has no milk in her udder.

\section{OVAROMHYSTERECTOMY OF THE PREGNANT UTERUS*}

By C. J. Rix, M.R.C.V.S., Royal Veterinary College, London.

22ND JUNE, 1900.-The subject was a Manchester terrier bitch weighing about $2 \frac{1}{2}$ pounds. The animal had been mated with a larger dog, and had been in labour for about twelve hours. As all efforts to deliver the pups by the natural passage failed, ovaro-hysterectomy of the pregnant uterus was performed under strict antisetic precautions through an incision, about 3 inches long, made in the middle line of the abdomen. The uterus contained two large pups, one of which measured $5 \frac{3}{4}$ inches from nose to tip of tail. This one had been much injured by the efforts made to deliver it, but the other was taken out, dried, wrapped in cotton wool, and put in a warm place. Three hours later it was given to a cat which had recently had kittens, the bitch herself being too much exhausted to suckle it. The latter was ordered brandy and milk every two hours during the next day and night, and for the two following days every four hours. Two stitches were removed on the sixth day, but beyond that the wound gave no further trouble. With the exception of a little constipation the bitch made an uneventful recovery. The puppy, too, is strong and well at the present date (2oth August), and was thoroughly attended to by its foster mother until it could be weaned.

\section{EMPYEMA OF THE NASAL CAVITIES IN A MARE.}

WITH NOTES UPON THE THERAPEUTIC VALUE OF SALINE IRRIGATION.

By W. M. ScotT, F.R.C.V.S., Bridgewater.

THE subject of this article was an aged dark-brown vanner.

Previous History.-Some three months ago we attended her for a bad attack of catarrhal influenza, which left, after the acute attack had subsided, a bilateral catarrh. This gradually improved under saline 